\title{
Methodology of numerical and experimental research of wind effects on high-rise complex
}

\author{
Olga Poddaeva ${ }^{1}$, Julia Gribach $^{1, *}$ \\ ${ }^{1}$ Moscow State University Of Civil Engineering 129337, 26, Yaroslavskoe shosse, Moscow, Russian \\ Federation
}

\begin{abstract}
Nowadays there is a tendency for the requirement toughening when the construction projects are designed. The existing standard and rule control in terms of the identification of the external load on buildings and constructions is directly connected with the reliability and safety control of building constructions, and one of the most important parts of the design is to take into account the wind effect. Air flows have a different impact on buildings due to their height; it is connected with the surface air existence. Consequently, the wind effect on the high-rise should be well-researched. The acting normative documents (SP 20.13330.2011 "Loads and impacts") formalize the inclusion of a special evaluation study of the wind conditions and aerodynamic property in the list of project documentation for the reliability and safety control of the high-rise building constructions. The identification of the wind conditions and aerodynamic property is available only in accordance with the theoretical and experimental analysis, of which a procedure is described in the present article.
\end{abstract}

\section{Introduction}

The development and progression of engineering of the construction provide a means of the new off-standard space planning decision creation and improve the activity of designers and architects. The high-rise building is not exception: today in most major cities of the world construction of skyscrapers is first ranks in the entire construction complex [1]. The buildings surpassing the height of $100 \mathrm{~m}$ can save the territory and also give opportunities to create the unique architectural masterpieces (fig. 1).

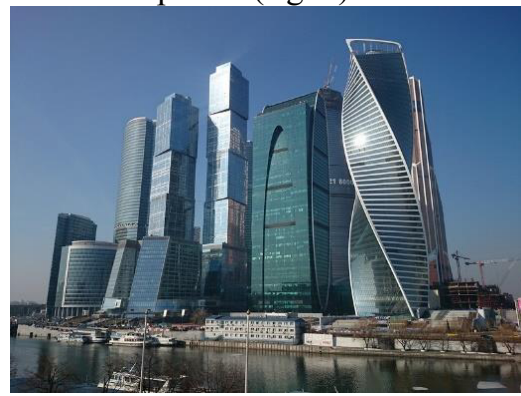

Fig. 1. High-rise buildings in Moscow (Moscow City)

\footnotetext{
Corresponding author: js-995@mail.ru
} 
However, despite the technological progress and the opportunity to create the unique structures, the main problem of architects and engineers, while developing the design documentation, is the procuring control of reliability and safety of constructions. First of all, this requirement applies to the high-rise, because high-rise buildings belong to the class of increased danger.

Based on experience, which gained of the monitoring of high-rise buildings, it was made a conclusion of the necessity of wind effect [2]. Firstly, construction of the skyscraper changes the surface air circulation conditions [3], what produces changes of climate near the building. Secondly, the building itself is adversely affected by the alternate wind load, which cause deformation of the high-rise building and destruction.

The hard research of the building design features and the evaluation of the area climate references encourage the improvement of reliability and safety of the skyscrapers while being affected by the wind load. The aerodynamics of high-rise buildings has own specificity. The coexisting of several factors of the wind effect impact on the structural analysis and calculations takes an important problem for architects and engineers: the lack of recommendations on the shape factor designation [4].

The acting normative documents (SP 20.13330.2011 "Loads and impacts") formalize the inclusion of a special evaluation study of the wind conditions and aerodynamic property in the list of project documentation for the reliability and safety control of high-rise building constructions. However, the all determination is available only by the test of the high-rise building layout in the architectural wind tunnels.

The aim of the present work is to describe the procedure of theoretical and experimental analysis of the wind effect on the high-rise buildings and constructions for their reliability and safety, which was produced in the laboratory of MGSU, and to approbate it on the example of the high-rise complex, which is situated in Moscow.

\section{Methodology}

The present work has the procedure of theoretical and experimental analysis of the wind effect, which was produced and approbated at the Educational research and production laboratory of aerodynamic tests of building construction of MGSU.

To realize the theoretical and experimental analysis of the wind effect on the high-rise complex it is necessary to implement sequentially the following steps:

- The climate terrain analysis, including the topographical and meteorological data analysis: the nature of the average wind speed change in level, the atmospheric turbulence structure, the average speed and turbulence dependence on the underlying surface roughness of the site are determined to evaluate the wind load.

- The designing 3D-model of the construction, the elaboration and layout with scale down, including the assessment of the construction project geometrical adjectives, the installation of the measuring equipment to determine the wind loads.

- The experimental research in the specialized wind tunnel and the processing of the obtained results.

- A series of numerical testing on the analytic model in the certified software (MGSU use software package ANSYS).

- The verification results of the theoretical and experimental analysis. In this case the allowable discrepancy mustn't exceed $15-20 \%$, otherwise the numerical modeling is repeated with the modified parameters of the grid and bounding actions until the acceptable convergence is achieved.

- The data analysis and the formulation of the conclusions and recommendations for ensure the structural reliability and safety. 
The experimental research realize at the Educational research and production laboratory of aerodynamic and aero acoustic tests of building construction of MGSU. The large gradient wind tunnel (fig. 2) of architectural type with 18,9 m long work space, use as a test rig. It allowed to simulate the surface atmosphere layer.

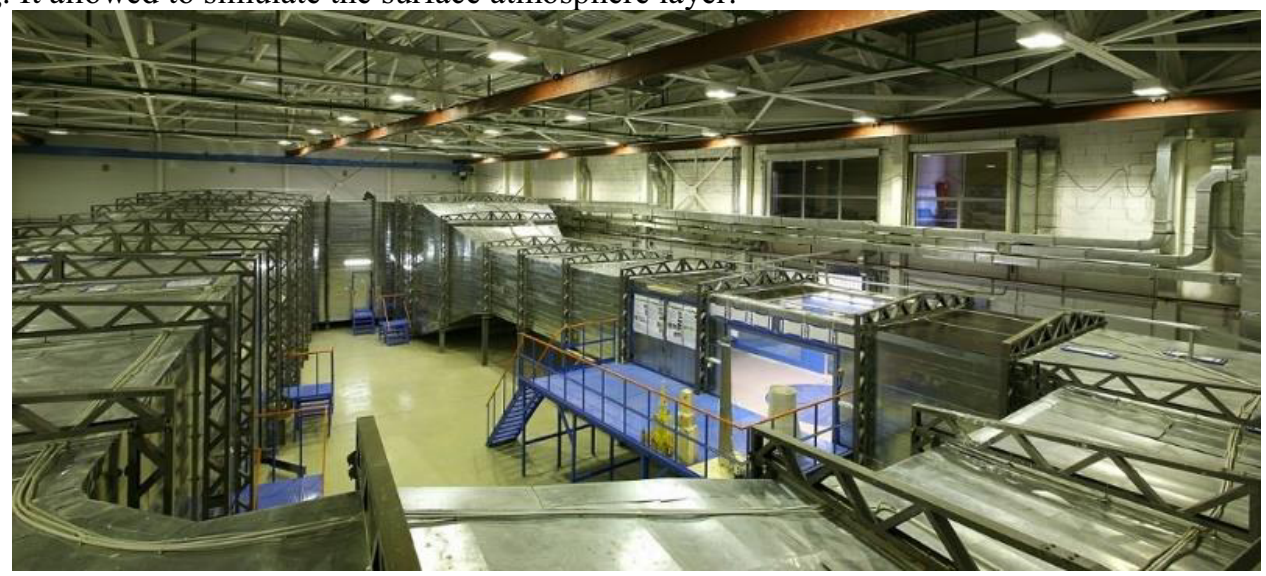

Fig. 2. Large gradient wind tunnel of laboratory of MGSU.

Moreover, for the aerodynamic researches the following equipment is being used:

- Integrated differential pressure sensors - MPXV7002DP. POP - from -2 to $2 \mathrm{kPa}$. The error after calibration is less than $0.5 \%$.

- Pitot pressure modification tube, designed to measure the volumetric flow rate of liquid and gas at one point of the cross section of the channel with an equivalent diameter of at least $300 \mathrm{~mm}$. It's used in determining the speed and volume flow in gas flues and ventilation systems complete with differential manometers.

- Differential digital differential pressure gauge DMC-01M with data processing is a device for measuring pressure, rarefaction and gas pressure difference, as well as for determining the speed and flow rate of gas and dust and air streams using Pitot pressure modification tubes.

- Six-component sensors for measuring the forces and moments of Schunk FTD. Main technical characteristics: measuring range Fx, Fy: $\pm 1000 \mathrm{~N}$, measurement range Fz: \pm 2500 $\mathrm{N}$, measuring range $\mathrm{Mx}, \mathrm{My}: \pm 120 \mathrm{Nm}$, measuring range Mz: $\pm 120 \mathrm{Nm}$, accuracy for measuring Fx , Fy, Fz: $\pm 1 / 16 \mathrm{~N}$, accuracy for measuring Mx, My: $\pm 1 / 160 \mathrm{~N} * \mathrm{~m}$, accuracy for measuring Mz: $\pm 1 / 320 \mathrm{~N}^{*} \mathrm{~m}$.

\section{Approbation}

The approbation of methodology is made using an example of a projected residential complex, located in the south of Moscow (fig. 4,a). The project includes 4 various-storey residential towers (height is 173 and $300 \mathrm{~m}$ ) and two-storey non-residential premises built into the stylobate. The towers are located along the perimeter of the site, forming a geometric arrangement with a individual well-maintained precinct.

As previously noted, primarily carried out a climate terrain analysis. A type of terrain is chosen in virtue of climate analysis under the requisition of SP 20.13330.2011 "Loads and impacts", and it's rated a relevant frontal velocity profile [5]. In this case, the type of development site corresponds to the type "B", a fig. 3 shows the velocity profile obtained in a wind tunnel. 


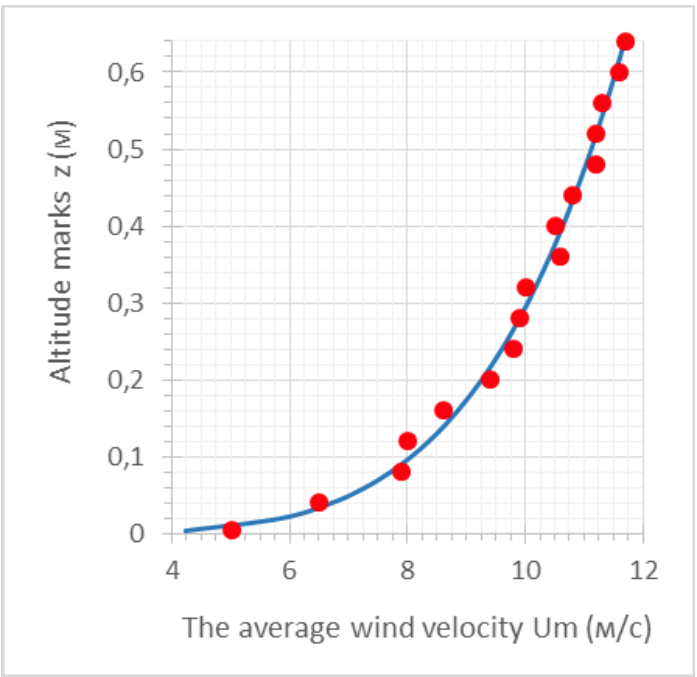

Fig.3. Dependency graph of average wind speed from altitude (for the "B" terrain type)

There were designed 3D-models of high building for the accomplishment of a number of computational tests (fig. 4, b) and made layout for experimental studies. The scale of the layout chosen from the conditions of adherence to the established limitations for this pipe (in this case, It is 1:250) (fig. 4, c) (GOST-R "Russian National Standard" 56728-2015. Buildings and constructions. Methods of determining the wind loads on enclosing structures). The drainage system installed to measure the velocity of flow and pressure at distinguished points (fig. 4, d). The pressure transferred through the holes in copper and silicone tubes to differential pressure sensors.
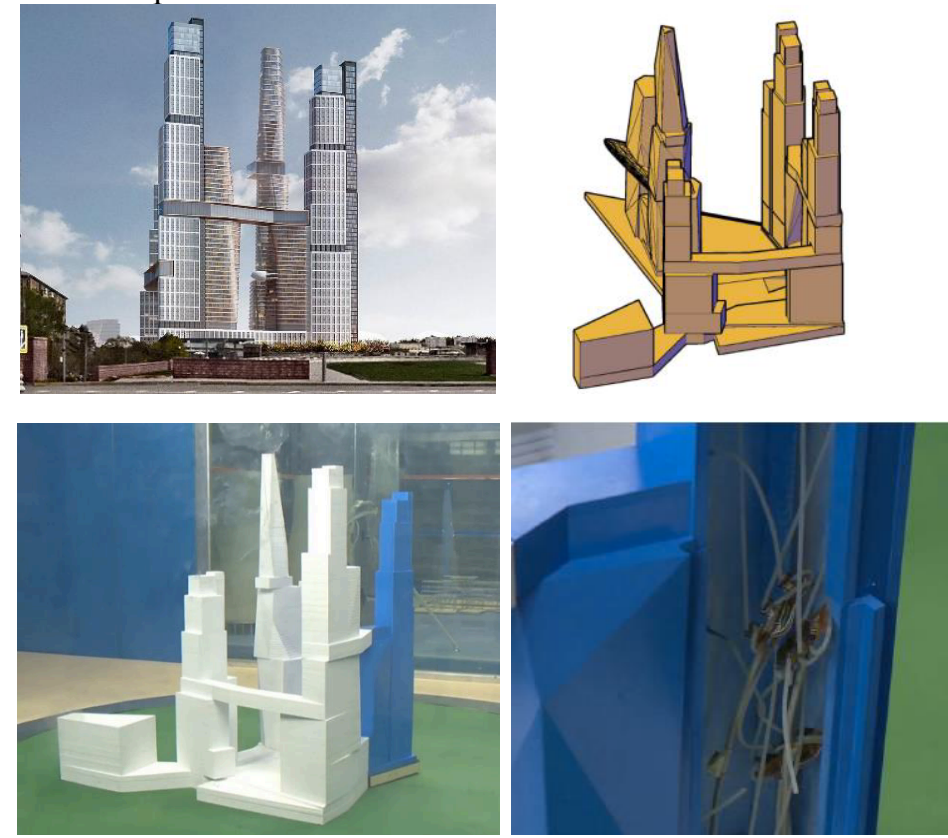

Fig. 4. Projected residential compound (a), 3D-models (b), a layout (c) mounting of a tube transfer system (d) 
The model of the explored complex installed on a specialized turntable in the wind tunnel workspace (fig. 5). After that, the tunnel is started up and the air flow is supplied to the model. Specific airflow velocity in the pipe is chosen to be sufficient for providing selfsimilarity according to the Reynolds number [6], when further velocity increase does not lead to a significant change of averaged values of shape factor in control points on the layout (GOST-R "Russian National Standard" 56728-2015). In this test, the wind speed in the work space was $15 \mathrm{~m} / \mathrm{s}$.

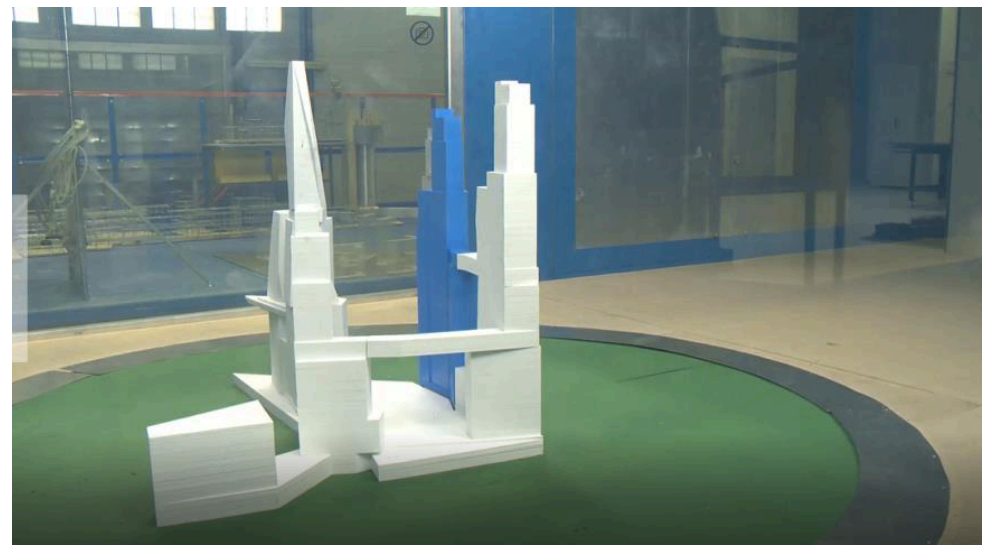

Fig. 5. Model of the explored complex in the wind tunnel workspace

\section{Results and discussion}

The result of the tests is the pattern of pressure distribution over the surface of the layout. According to the received data, it is possible to calculate the average values of the pressure shape factor for different angles of wind attack, from $0^{\circ}$ to $360^{\circ}$, using formula (1).

$$
C_{p}=(2 * p) /\left(\rho * v^{2}\right),(1)
$$

where $\mathrm{C}_{\mathrm{p}}$ is a coefficient of pressure;

$\mathrm{p}$ is a pressure (obtained by the experimental method);

$\rho$ is a density of air (at a temperature of $+20^{\circ} \rho=1,2041 \mathrm{~kg} / \mathrm{m}^{3}$ );

$v$ is a speed of air $(15 \mathrm{~m} / \mathrm{s})$.

In the same way it is possible to calculate peak values of pressure shape factor, necessary for calculating the peak component of the wind load on enclosing structures and facade systems.

Also during the experimental studies using 6-component strain-gage weigher and software ATI DAQ F/T can identify total forces $F_{x}, F_{y}$ and $M_{z}$ and a torque along the axes $\mathrm{X}, \mathrm{Y}$ and $\mathrm{Z}$, can also calculate total shape factors of resistance to axes $\mathrm{X}, \mathrm{Y}$ and $\mathrm{Z}, \mathrm{C}_{\mathrm{x}}, \mathrm{C}_{\mathrm{y}}$ and $\mathrm{CM}_{\mathrm{z}}$ on which can make a shape factor dependency graph $\mathrm{C}_{\mathrm{x}}, \mathrm{C}_{\mathrm{y}}, \mathrm{CM}_{\mathrm{z}}$ with a change in the angle of attack from $0^{\circ}$ to $345^{\circ}$ (fig. 6).

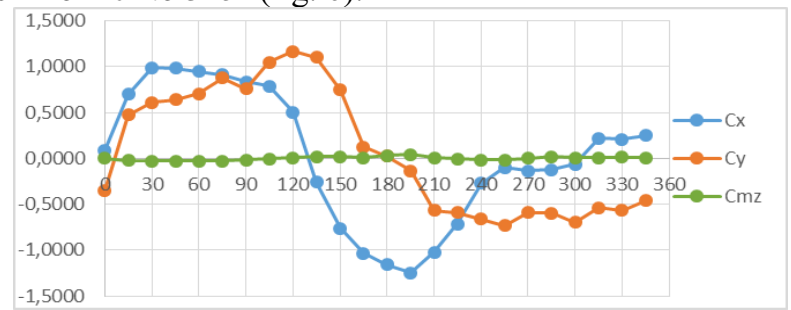

Fig. 6. Shape factor dependency graph $\mathrm{Cx}, \mathrm{Cy}, \mathrm{Cmz}$ with a change in the angle of attack from $0^{\circ}$ to $345^{\circ}$ 
Numerical simulation of the flow around the building is carried out in parallel with the implementation of experimental studies to clarify wind load data. Performing computer calculations it is computed the unsteady flow and the distribution of the dimensionless pressure coefficient $\mathrm{Cp}$ by the facades along the perimeter of the horizontal section of the building and height along the building [7]. For the numeral studies realization it is necessary to install computational grid with the necessary grinding (fig. 7) and establish the boundary conditions.

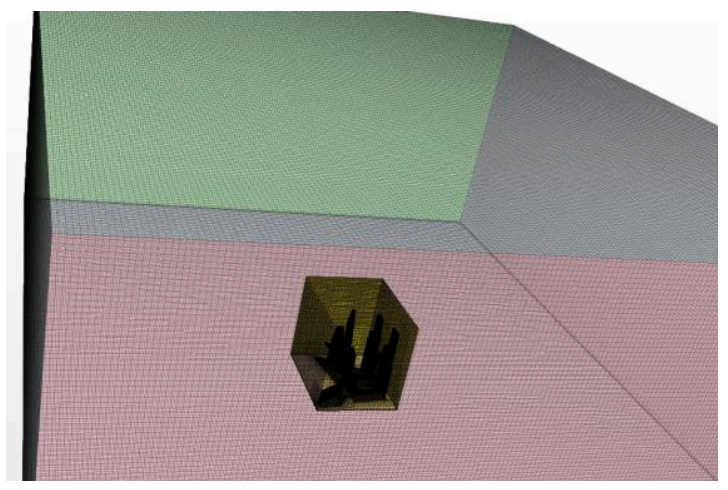

Fig. 7. General view of computational grid

Reliability of the results of numerical simulation is confirmed by the use of a certified software bundle ANSYS and by the results of the verification tests. In this project it showed good consistency of the calculated data with the experimental data (the discrepancy of the data wasn't more than $20 \%$ ).

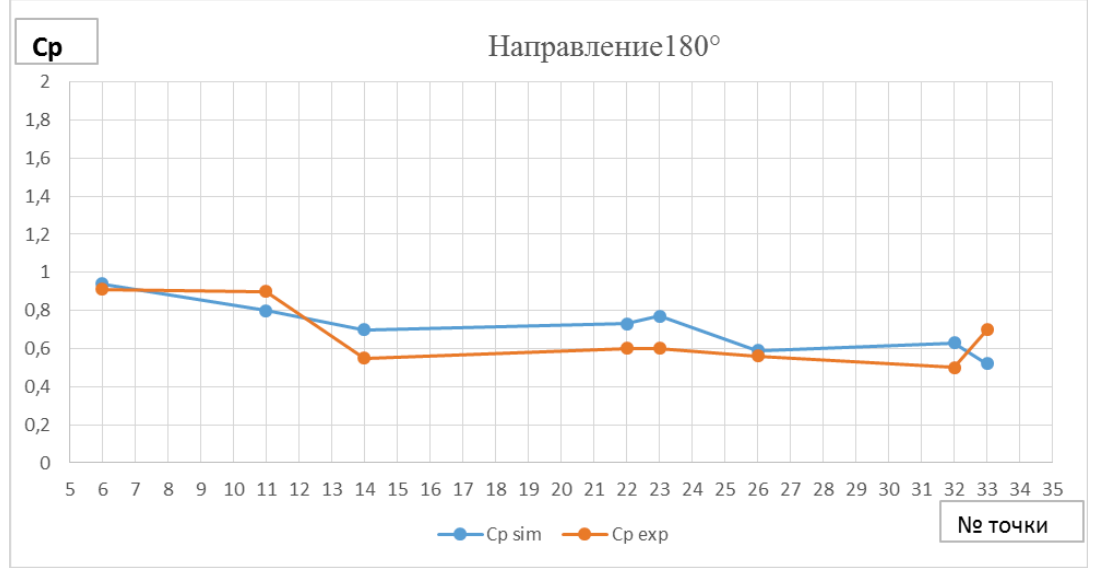

Fig 8. Verification test results

Fig. 9 shows the distribution patterns of the average pressure shape factor on the facades of high-rise buildings. Numerical modeling provides more complete information, which is necessary for the wind load calculation (the results of experimental studies are distinct states at points on the layout surface) [8], it also identifies all problem areas. 


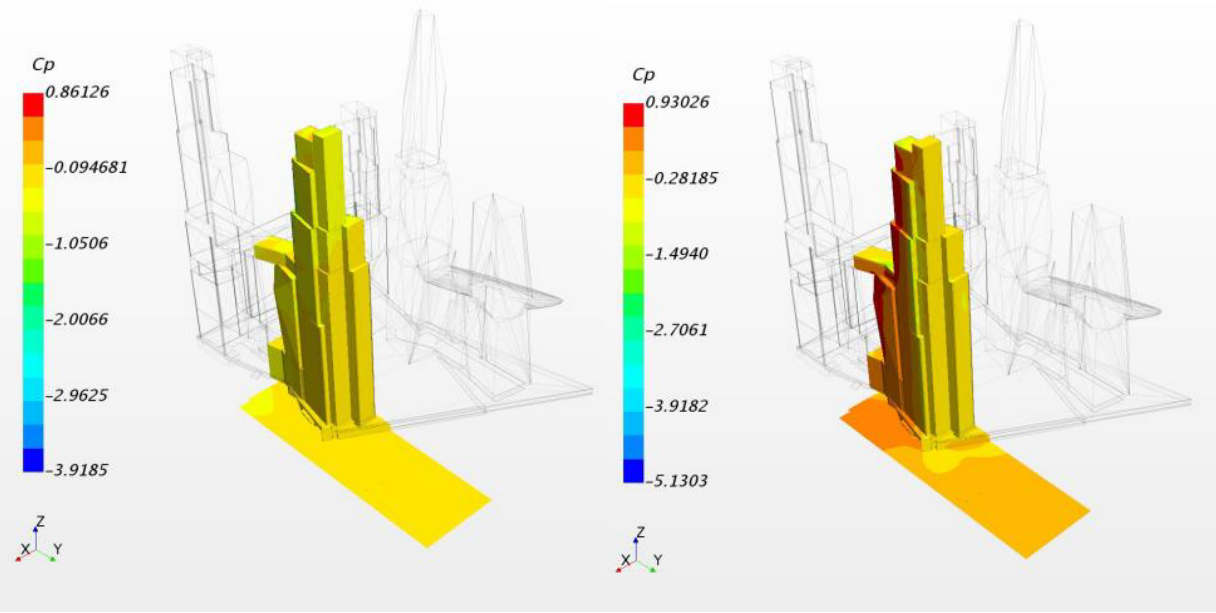

Fig. 9. Distribution of the average pressure shape factor on the facades of high-rise buildings of the explored residential complex for $0^{\circ}$ and $45^{\circ}$

\section{Conclusions}

A methodology of numerical and experimental research of wind effects on high-rise complex has been developed.

In the framework of approbation of the developed methodology, the following results were obtained: patterns of wind pressure distribution along building facades, average and peak values of aerodynamic coefficients, and dimensionless aerodynamic coefficients.

Due to the obtained results, it can be asserted that the average values of the pressure shape factor are approximately in the range $\pm 1,5$. At the same time, there are zones of increased pressure at the corner areas of facade structures with the peak values: $3-3,5$.

The values of the dimensionless shape factor $\mathrm{Cx}, \mathrm{Cy}, \mathrm{Cmz}$ are defined relative to the center of the base of the explored object, the maximum values of the coefficient $\mathrm{Cx}$ arise at the blowing angles $30^{\circ}$ and $195^{\circ}(\mathrm{Cx}=0,98$ and $\mathrm{Cx}=-1.24)$. In general, the obtained values are well correlated with the shape factor values, which are considered in SP 20.13330.2011 "Loads and impacts", and do not exceed them, so the need to develop specialized recommendations for the redesign is excluded $[9,10]$.

Using the values of the shape factor obtained during the processing of calculated and experimental data values, the designer can independently determine the average and peak values of the wind load per unit area of the building facade in accordance with the requirements of SP 20.13330.2011 "Loads and impacts".

It should be noted that a multifaceted approach is important to the solution of project tasks that ensure safety and reliability of high-rise buildings and constructions. It should include the work of both engineers and scientists. Currently, there is no other system that simplifies the implementation of this procedure, because the design of unique buildings with a height more than $100 \mathrm{~m}$ is quite a challenge [11].

\section{References}

1. O.I. Poddaeva, Y.S. Buslaeva, D.S. Gribach, Advanced Materials and Engineering Materials IV, 246-249 (2015) 
2. O.I. Poddaeva, Y.S. Buslaeva, D.S. Gribach, Newsletter of the BSTU (Belarusian State Technological University) V.G. Shukhova, 6, 58-62 (2014)

3. O.O. Egorychev, P.S. Churin, Housing construction, 6, 20-22 (2015)

4. O.I. Poddaeva, I.V. Dunichkin,S.A. Andreeva, Materials of the international practical conference. Effective organizational and technological solutions and energy-saving technologies. Kharkov, 64-66 (2014)

5. O.I. Poddaeva, Industrial and civil construction. 9, 35-38 (2013)

6. D. Čehel'ová, M. Janák, B. Bielek, Applied Mechanics \& Materials. 820 (2016)

7. O.O. Egorychev, S.I. Dubinsky, A.N. Fedosova, Applied Mechanics and Materials, 713-715, 1729 (2015)

8. S.V. Gouvernyuk, V.G. Gagarin, Journal “ABOK” (Russian Association of Engineers for Heating, Ventilation, Air-Conditioning, Heat Supply and Building Thermal Physics). 16-22 (2007)

9. Q. Yong, G. Ming, T. Yukio, Wind and Structures, 8, 5, 309-324 (2005)

10. H. Dongmei, Z. Ledong, D. Quanshun, Z. Xue, C. Wei, Journal of Fluids and Structures, 69, 355-381 (2017)

11. A. Stepek, I.L. Wijnant, Interpolating wind speed normals from the sparse Dutch network to a high resolution grid using local roughness from land use maps // KoninklijkNederlandsMeteorologischInstituut, Technical Report TR-321. - (2011).

12. A. Stoffelen, J. Vogelzang,. Wind bias correction guide // KNMI, Version. - (2011)

13. P. Irwin, R. Denoon, D. Scott D. Wind Tunnel Testing of High-Rise Buildings. // Routledge, (2013)

14. F. Fan, et al., PowerTech, 2015 IEEE Eindhoven, IEEE, 1-6 (2015)

15. A. Allik, et al., Agronomy Research, 12, 2, 433-444 (2014) 